Stream: Inspiring Critical Thought

2017, Vol 9(2), pp. 26-44

(C) The Author(s), 2017

http://journals.sfu.ca/stream

\title{
What's in a Word? Unpacking the Communicative Implications of Knowledge Translation as a Term.
}

\author{
Christine Ackerley \\ School of Communication \\ Simon Fraser University
}

\begin{abstract}
Knowledge translation is one of many terms used to describe the process of moving academic research into practical application to achieve positive impacts. Attention to knowledge translation has grown significantly in the contemporary Canadian research landscape, supported by major federal research funders. This article explores the term in depth, highlighting the interdisciplinary links between the burgeoning area of knowledge translation and more established areas of communication studies and translation studies. Focusing on a Canadian health research setting, the concepts of "perfect communication" and "loss in translation" are examined in relation to knowledge translation. This analysis explores contradictions and tensions within current assumptions and rhetoric around knowledge translation, highlighting misalignments with traditional thinking about communication. These issues can affect how knowledge translation work is perceived and practiced. Critical attention to the tensions emerging from the term knowledge translation is important for the field to continue to develop.
\end{abstract}

\section{Keywords}

knowledge management, knowledge translation, ideology, translation studies

\section{Introduction}

The last two decades have seen an explosion of interest in how contemporary societies can close the gap between what is known, and what is done (Davis et al. 2003; Jacobson, 2007). A plethora of terms have been used to describe the complex process of accelerating the use of research-based knowledge into real world settings, including knowledge translation, knowledge mobilization and knowledge exchange. In one review, McKibbon et al. (2010) identified more than 100 different terms of this kind used throughout multi-disciplinary literature.

Some scholars have passionately argued that establishing a common nomenclature is vital to the advancement of the field, and that this confusion and lack of clarity around terms is a problem of the utmost importance (Cordero et al., 2008; Gaglardi et al., 2008; Kerner, 2006; McKibbon et al. 2010). However, others have argued that terminology and jargon should not be a central concern for knowledge translation, contending that terms should be accepted as basically synonymous, and research should focus on more important matters, such as elucidating best practices (Shaxton et al., 2012). This article seeks to blend those perspectives in a different approach towards terminology, by probing a key term in the Canadian health research context — "knowledge translation" - to explore its theoretical and practical implications in greater depth. Rather than outlining the subtle differences between terms and their meaning in relation to each other, this article seeks to present 
a more complete understanding of one term, including its historical roots and the ways in which it might shape practice and theory.

First, I briefly introduce knowledge translation as a concept, delineate the scope of this article, and explore some links and tensions that emerge between knowledge translation and the fields of communication studies and translation studies. Then, I probe what we can learn from the underlying meanings and assumptions of "translation" within the context of knowledge translation. Bringing the advantages and pitfalls of knowledge translation as a term to the fore, connects the relatively new field of knowledge translation with the more established traditions of communication studies and translation studies, potentially providing a richer range of approaches and theories for knowledge translators to be aware of and draw upon.

\section{Definitions and Scope}

While the term knowledge translation is a recently emerged phenomenon, the concept, practice and study of putting research findings into practice is not new. Gabriel Tarde's work in the late 19th century, and Everett Rogers' later work in the 1960s examined diffusion of innovation, which explored questions about the spread of ideas and knowledge within social systems (Green, Ottoson, García, \& Hiatt, 2009, p. 152; Rogers, 2003). In nursing research, the term "research utilization" has been widely used since the 1970s (Kirchhoff, 2004). Therefore, it is important to recognize that terms such as knowledge translation have not introduced the concept, but rather sought to name and present the idea in a new way.

While the literature offers many possible definitions of knowledge translation, for the purposes of this article I will use the Canadian Institutes for Health Research (CIHR) definition of knowledge translation as:

The exchange, synthesis and ethically-sound application of knowledge--within a complex system of interactions among researchers and users--to accelerate the capture of benefits of research for Canadians, through improved health, more effective services and products, and a strengthened health care system. (Canadian Institutes of Health Research, 2014)

The CIHR definition is the most commonly cited definition of knowledge translation, and has been widely taken up by other organizations and scholars (Azimi, Fattahi, \& Asadi-Lari, 2015, p. 96). Knowledge translation processes can take varied and diverse forms. For example, knowledge translation practices range from writing better research summaries (Moat, Lavis, \& Abelson, 2013) and best-practice guidelines (Berta et al., 2010), to designing eye-catching infographics (Crick \& Hartling, 2015) and gamifying the latest research (McKeown, Krause, Shergill, Siu, \& Sweet, 2016). Thus, knowledge translation describes many diverse strategies attempting to better move evidence into practice.

Many different disciplines - such as women's studies, political science, evaluation and social work - have rich histories of knowledge-to-action practices and research (Balka, 1991; Heinsch, Gray, \& Sharland, 2016; Patton, 2016). However, their different terms-of-choice often create disciplinary and sometimes geographic silos (Contandriopoulos et al., 2010; Tabak, Khoong, Chambers, \& Brownson, 2012; Ward, 2016). For example, "knowledge mobilization" is the go-to term for Canadian social scientists (Social Science and Humanities Research Council., 2009), whereas "knowledge transfer" dominates the UK technology and commercialization space. However, I chose to focus this exploration on knowledge translation in Canadian health research for several reasons. 
The life-or-death stakes of healthcare make it arguably one of the more urgent settings for research to be translated quickly into action, and healthcare is one of the most-studied contexts for knowledge-to-action work to date (Azimi et al., 2015). Yet, health research often takes more traditional biomedical and/or positivist perspectives, while knowledge translation can sometimes involve more constructivist, critical and/or social science approaches (Greenhalgh, Jackson, et al., 2016). Therefore, health research can provide particularly interesting cases of clashing worldviews, misunderstandings, and divergent uses of key terminology.

I also chose to focus on a Canadian context, because Canada is a world leader in knowledge translation. Many researchers in other countries note Canada is on the leading edge of integrated knowledge translation research, theory and practice, and that the Canadian Institutes of Health Research (CIHR) is a champion for knowledge translation on the world stage (e.g. Goldner et al., 2011; Smith \& Stewart, 2016; Ward, 2016).

This article focuses on knowledge translation in both applying the results of research evidence to healthcare practice (sometimes called bench-to-bedside translation), and decision making by healthcare providers, administrators, and policy makers. While knowledge translation of evidence to broader, public audiences is also an important area, an in-depth discussion of public-focused knowledge translation is outside the scope of this article.

Throughout the article I mention the "knowledge translation community," and this encompasses the collection of people involved in the practice, study and funding of knowledge translation and related work. It is also important to define "knowledge," at least as used in the context of this article. Philosophical questions about the nature of knowledge and explorations of epistemology have produced many possible definitions of knowledge. For this article, I use the broadest common-use definition of knowledge as "facts, information, and skills acquired through experience or education" ("Knowledge," 2015). This definition most completely encompasses the diversity of knowledge that might be part of a given knowledge translation activity.

Translation is another key concept that resists exact definition. In general use, translation is defined as an act, process, or instance of a rendering from one language into another, and also the product of such a rendering ("Translation," 2015). In a different context, it can also refer to a conversion: a change to a different substance, form, or appearance ("Translation," 2015). However, for the purposes of this article, I will draw from the field of translation studies for more nuanced definition. Influential linguist Roman Jakobson (2000/1959) proposed definitions for what he argued are the three types of translation. Interlingual translation refers to interpreting signs across one or more languages or sign systems, and is the most prevalent conception of translation (Jakobson, $2000 / 1959$, p. 114). Intersemiotic translation refers to a process of transmutation such as translating a poem into dance form (Jakobson, 2000/1959, p. 114). Intralingual communication refers to substituting apparently comparable "signs" within a specific language or sign system, such as rewording (Jakobson, 2000/1959, p. 114). To open up broader, interdisciplinary questions around translation, I use Jakobson's definition of the three types of translation, and focus on intralingual translation.

\section{The Rise of Knowledge Translation}

Interest in knowledge translation has grown significantly over the last two decades among granting councils, policy makers or practitioners, and academics (Balka et al., 2015; Graham et al., 2006; Grimshaw Eccles, Lavis, Hill \& Squires, 2012). This may stem from a growing awareness that research findings are not making their way into practice in a timely manner (by fast-paced, modern standards), stimulating rejuvenated interest in finding ways to maximize and hasten knowledge 
translation (Graham et al., 2006, p. 14). Additionally, Kerner and Hall (2009) emphasized that the earlier work on knowledge translation was based on a pre-20th-century model of communication, focused on how knowledge was translated through word of mouth and written publications (p. 520). With the introduction of the Internet and other, more rapid communication technologies, access research findings has sharply increased, alongside new pressures to more rapidly translate research insights into application (Kerner \& Hall, 2009, p. 520).

Graham et al. (2006) have additionally argued that government and business' current zeitgeist of evidence-based, cost-effective, and accountable decision making has likely increased interest in the potential of knowledge translation to affect positive change and support better decisions (p. 14). More than ever, we culturally embrace the concepts of knowledge workers, in a knowledge-based economy where knowledge is regarded as the most critical resource, at constant risk of being lost or underused (Liyanage et al., 2009, p. 118).

The rise of knowledge translation can also be traced to its introduction and institutionalization by national and international research granting councils. For example, the Canadian Health Services Research Foundation organized a national workshop in 1999 and called for increased efforts to translate scientific research to better meet decision makers' needs (Canadian Health Services Research Foundation, 1999). In 2000, the government created CIHR with the mandate to create new health research, and also translate that research for real world use (CIHR, 2014). Then, in 2004 Canada's Social Sciences and Humanities Research Council (SSHRC) launched its version of knowledge translation, termed "knowledge mobilization," in order to encourage "the flow of knowledge among multiple agents leading to intellectual, social and/or economic impact" (SSHRC, 2009 , p. 4). Other agencies likewise prioritized knowledge translation, including the National Health Service in the United Kingdom and the National Institutes of Health in the United States, and the World Health Organization (Burns, 1998; Woolf, 2008; World Health Organization, 2004, p. 3). Granting councils' introduction and emphasis of knowledge translation in the late 1990s and early 2000s has subsequently shaped the trajectory of knowledge translation and cemented it as a key priority. However, the process of conducing, understanding and researching knowledge translation has been challenging.

\section{What's in a Name? "K*” and the Struggle with Terminology}

The literature from the knowledge translation community is divided about the significance of terminology, however most researchers agree there is considerable uncertainty around terms (Cordero et al., 2008; Graham et al., 2006; Kerner \& Hall, 2009; Straus, Tetroe \& Graham, 2009; Tetroe et al., 2008). A study by Graham et al. (2006) identified 29 terms related to the concept of "knowledge to action," used across 33 research funding agencies and nine countries. In other reviews of the literature, Ward, House and Hamer (2009) found 58 different terms and Straus et al. (2009) cited over 90 terms. More recently, McKibbon et al. (2010) found 100 terms describing knowledge translation in the literature from healthcare alone. Historically, different sectors have chosen different terms, and then stuck with them over time to maintain some continuity (Balka et al., 2015). Additionally, as more knowledge translation is deliberately practiced and researched, new terms have been introduced to better characterize the concepts and practices as experience grows (Shaxson et al. 2012, p. 2). Meanings and definitions of existing terms can also be adapted. For example, Balka et al. (2015), found that while the term "knowledge transfer" is often criticized for implying a one-way flow of knowledge, some researchers use knowledge transfer to describe a two-way flow, or cyclical flow (p. 5), suggesting that researchers might redefine a term to suit their work, sometimes contradicting existing assumptions or understandings about the term. 
Of the myriad possible terms to analyze, there are several key reasons why knowledge translation provides a particularly interesting starting point. Firstly, many scholars have already made persuasive cases for why knowledge translation is the most appropriate term (Liyanage et al., 2009; Major \& Cordey-Hayes, 2000). In much of the literature, the push for "knowledge translation" instead of "knowledge transfer" is portrayed as a more sophisticated recognition of multi-step, multiactor processes (Armstrong et al., 2006; Balka et al., 2015; Bowen \& Martin, 2005). Holden and Von Kortzfleisch (2004) have proposed the study and practice of intralingual translation was a relatively unexplored, yet fruitful conceptual resource for the knowledge translation community (p. 128). They have argued translation is historically and inextricably linked to knowledge translation processes, because "translation is by far the oldest universal practice of conscientiously converting knowledge from one domain to another" (Holden and Von Kortzfleisch, 2004, p. 129).

In addition to the existing arguments in favour of knowledge translation as the most suitable term, it is also one of the most salient terms within a Canadian healthcare context, because it is the choice term of CIHR (Straus et al. 2009), in addition to influential groups including the NIH in the United States and the WHO. Graham et al. (2006) found that out all the terms they reviewed, knowledge translation was the one that has gained prominence in Canada (p. 14).

In the debate over terms and their significance, some in the knowledge translation community have argued that all terms should basically be understood as synonyms, and that questions of terminology should not be central concerns in knowledge translation research or practice (Lang et al. 2007). Along these lines, Lang et al. (2007) have argued that since most terms originated long after the practice and concept of knowledge translation existed, all of these terms mean essentially the same thing (p. 355). It is common for researchers (e.g. Armstrong et al., 2006; Graham et al., 2006; Scott et al., 2008) to list popular synonyms discussing knowledge translation, and Ottoson (2009) has argued that these terms are then tossed around often informally and lightly in research and practice (p. 12). Some practitioners have attempted to erase the confusion of terminology by suggesting the acronym " $\mathrm{K}^{*}$," where the asterisk can stand for any of the words that typically follow "knowledge" (Institute for Knowledge Mobilization, 2014; Shaxson, 2012).

The other, seemingly more popular, side of the terminology debate calls for a standardization of terminology, and sees the choice of terms as vital to the success of the knowledge translation community (Rycroft-Malone, 2007; Cordero et al., 2008; Kerner, 2006). Researchers have outlined a dearth of meaningful and consistent definitions of the terms, despite the considerable and growing interest in the topic (Estabrooks et al, 2006; Graham et al., 2006). Furthermore, it has been argued that the misuse of the terms in some settings has led to their status as buzzwords and creates damaging lack of clarity about the concepts and components involved (Graham et al., 2006, p. 14). Estabrooks et al. (2006) argued that unclear terminology and implicit assumptions often hinder advancements in the field, that most of the literature rests on assumptions that are rarely made explicit, and investigators often wrongly assume that terminology is a subsidiary concern. Azimi et al. (2015) contend there is a growing concern in the knowledge translation community about the present terminology situation, where "too many fuzzy or ill-defined concepts are used and scientific as well as practice-related communication is severely distorted and hampered" (p. 97). This echoes Graham et al. (2006), who proposed that gaining consensus on terms and definitions is essential if knowledge producers, implementers and users are to effectively and meaningfully communicate with each other (p. 22). Many researchers in this camp attempt to organize the multitude of terms within indexes, matrixes, and glossaries, to better highlight differences and similarities in meaning between terms (Balka et al., 2015; Graham et al., 2006; Ottoson, 2009).

This article seeks a pragmatic middle ground between the stances of terminology as "inconvenient but unimportant," versus "terminology as the vital foundation for future work." Following Otto- 
son (2009), it is useful to unpack the implications of each term, and whether and how it might affect our understandings (p. 18). For example, Ottoson (2009) has demonstrated how terms implicitly suggest different questions, theoretical assumptions and problems in the context of moving knowledge into action:

Did intended beneficiaries have the authority or opportunity to use a new skill (implementation theory)? Were ideas translated into actionable messages for intended beneficiaries (translation theory)? If intended beneficiaries shared but did not use their program experience, does that spread of knowledge count as nonuse or success (diffusion theory)? (p. 8)

Being aware of the implications and deeper meanings embedded in terms has benefits beyond a better understanding within the knowledge translation community. These terms are not commonly used outside of a narrow, knowledge translation context, and it is important to gain a more nuanced understanding of what a term might convey to people not initiated in the knowledge translation discourse including groups such as politicians, community research partners, and healthcare practitioners. As Bowen and Martens (2005) have suggested, these groups are potentially unfamiliar with many knowledge translation terms, and might lack the understanding that many are used as synonyms. This article takes the approach that the existing disarray of terms is unlikely to clarify any time soon, because various terms are deeply embedded within different contexts. However, rather than discount all terms as synonymous, terms should instead be probed for their deeper assumptions and then connected with the broader context of their history, shifting use and possible implications.

\section{Drawing Connections between (Knowledge) Translation and Communication}

Knowledge translation has historically drawn from early communications models to conceptualize its processes. Shannon and Weaver's (1949) basic, mathematical model of communication is cited surprisingly often in knowledge translation literature (for example, in Major \& Cordey-Hayes, 2000, p. 412; Carlyle, 2004, p. 555; Liyanage et al., 2009, p. 123, Jacobson, Butterill \& Goering, 2003, p. 94). Shannon and Weaver's Mathematical Theory of Communication is also widely accepted as one of the main seeds out of which communication studies grew (Fiske, 1990, p. 7), which suggests an underexplored historical link between the theoretical genealogy of the two fields. Additionally, Katz and Lazarsfeld's two-step flow model has also been used to explicate knowledge translation, however researchers tend use the two-step-flow model alongside Rogers' more complex diffusion of innovation theory, and Tarde's work on personal influence, social networks and public opinion (Katz, 2006; Srivastava \& Moreland, 2012).

Communication also factors into discussion of knowledge translation in a very practical sense, because knowledge translation activities necessitate actual communication. Specialized research must be communicated to achieve any of knowledge translation's practical goals. So, in addition to suggesting questions about organizational behaviour, psychology, social and contextual factors and evaluation, knowledge translation also poses some of the classic communications questions: how do senders know if their messages are received? What are the effects of different communications? Or, what communications channels and media forms best convey knowledge to those who seek it?

There have also been several explorations into conceptualizing all communication as translation. For example, Hatim (1990) argued translation parallels all human communication, and conceptualizing communication as translation encourages deeper investigation of the signs of a culture, and social and individual motivations for language choices (p. ix). Likewise, Bell (1991) contended that 
all communicators are translators. Following this trend, Palsson (1994) noted translation studies' growing, cross-disciplinary interest in communication. Similarly, Jacobson (2007) has argued that while knowledge translation has traditionally drawn more from the fields of anthropology and organization studies, communications theories are gaining popularity as resources for knowledge translation researchers (Jacobson, 2007, p. 118).

In the discipline of communication, Ogden and Richards (2001/1923) took up translation as an area of critical inquiry, and demonstrated how the practice and critical analysis of translation could highlight important issues related to communication, including a better understanding as to how and why misunderstandings occur, and how people can understand each other when they seem to be using different signs. However, Striphas (2006) argues that, with a few exceptions, translation has since faded from the communication discipline's repertoire of key concepts (p. 234). These various connections between communication, translation and knowledge translation provide a rich foundation from which to start exploring the implications of knowledge translation as a term.

\section{Probing Assumptions and Mining for Meaning}

Rather than write off knowledge translation as one of many empty buzzwords, it is more productive to explore and probe the term's possible (and sometimes contradictory) assumptions and implications. Some of these assumptions could hinder the project of knowledge translation, especially if not made explicit and addressed in practice and study. Still, others provide useful resources that could support knowledge translation efforts by emphasizing important questions and theoretical avenues to pursue. In this investigation, I focus my analysis on the "translation" half of the term. Other scholars, such as Greenhalgh (2010) have fruitfully explored the assumptions and meanings around "knowledge" in a knowledge translation context. This article thus contributes to a better understanding of the term as a whole. While the focus is on the micro-level of a specific term, it has broader implications for our understandings of practicing and theorizing knowledge translation.

Many scholars have attempted to untangle and explain the complex relationships between language, meaning and culture (Everett, 2005; Perlovsky, 2009; Skerrett, 2010). Some posit that language determines culture, while others argue culture determines language (Reboul, 2012, p. 309). Extending the latter, it has also been argued that words have no fixed meaning outside the context in which they are used (Greenhalgh \& Wieringa, 2011, p. 503). In unpacking the meaning of the term knowledge translation, I take the approach that language and cultural meanings have a reciprocal relationship. This follows Lotman's theory that "no language can exist unless it is steeped in the context of culture; and no culture can exist which does not have at its centre, the structure of natural language" (Lotman \& Uspensky, 1978, p. 212). So, words and language--in this case, the term knowledge translation, are understood to both shape and reflect culture. In this frame of understanding, existing (Western, North American, English-language) understandings of translation shape our ideas of knowledge translation, but the term can also suggest or create new meanings and assumptions over time or in different contexts.

Knowledge translation as a formalized term is only approximately 15 years old, but its components, knowledge and translation are ancient concepts. This creates an interesting clash in meanings. As it has been introduced and used in the knowledge translation community, the term encompasses many assumptions that support the aims of knowledge translation work. However, taking a historical perspective on the term knowledge translation reveals more potential drawbacks, because translation becomes problematic when judged against normative ideals of communication (Striphas, 2006; Peters, 1999). However, drawing from the fields of translation studies and com- 
munications studies offers alternative ways to approach questions of the success or failure of knowledge translation efforts.

\section{Traditions in Communication Thought}

This section provides a brief overview of two particularly relevant traditions in communications thought, as they relate to understanding knowledge translation: conflation of communication and progress, and the spiritualist tradition. Knowledge translation as a concept picks up the historical thread of conceptualizing communication as inherently associated with modern progress. Mattelart (1996/2007) argued that the emergence of communication as a rational social project stems from the idea of the "perfectibility of human society" (p. 29). In his case of $17^{\text {th }}$ and $18^{\text {th }}$ century France, for example, engineers sought to "bring men together," literally by building bridges in service of unrestricted, rational communication to advance the prosperity of the nation (Mattelart, $1996 / 2007$, p. 34). Thus, communication is a tool to "purge semantic dissonance and thereby open a path to more rational social relations" (Peters, 1999, p. 12). It also means that ideas of communication became associated with ideals like universal community and progress (Craig \& Muller, 2007, p. 2). This thread of thinking about communication has continued and become interwoven in current assumptions underlying knowledge translation. Knowledge translation efforts are most often described using the rhetoric of progress (Balka et al., 2015, p. 7). Knowledge translation is understood as a rational social project, which removes inefficient obstacles between people and enables knowledge (a valuable resource) to flow freely amongst people and organizations. It is thus also assumed to speed up research, allow new discoveries to be made, make research funding more efficient, and apply medical knowledge more quickly than would otherwise be the case (Balka et al., 2015, p. 7). In this way, the knowledge translation community draws on some traditions in communications thought to construct knowledge translation efforts in a positive, progressive and rational light. Of course, "communication as progress" is not the only tradition in communications theorizing, and there are many other ways that "communication" has been thought about throughout history (Craig \& Muller, 2007).

In his influential monograph Speaking into the Air, John Peters (1999) traced historical ideas of communication, and argued the dominant view of successful communication today remains based in Christian religious thinking, called the "spiritualist tradition" (Peters, 1999, p. 17). Peters (1999) outlined how Saint Augustine, an early Christian theologian and philosopher, was a key figure in linguistic theory who built the dream of transcending an "interior self" through communicating (Peters, 1999, p. 20). Augustine popularized the idea of unmediated, spirit-to-spirit linkage as the normative vision of how communication ought to work, and saw human words as imperfect vessels striving but failing to authentically transmit meaning (Peters, 1999, p. 63). Angels were presented as communicative exemplars, because they could use spiritual or mental telepathy to transmit meanings from one mind to another, without the inevitable falseness or distortions of embodiment and speech (Peters, 1999). These ideas of perfection and failure have persisted in our much of our thinking about communication since Augustine, and have framed how the many problems and goals of communication have been understood.

For example, Ogden and Richard (1923/2001) explored how to best eliminate controversy and confusion in human communication by reducing discrepancy or clouded meanings (Peters, 1999, p. 17). The threads of spiritualist communication thinking also appear in semiotic tradition. Following the assumption that ordinary communication always falls short, Locke's semiotic theory aimed to explain how careful use of language could bring humans closer to each other and the ultimate ideal of angel-like communication (Craig \& Muller, 2007, p. 2). Many other explorations of normative 
communication support Peters' analysis, arguing the ideals of perfect communication are impossible to fulfill in reality and distract us from other, potentially more useful and interesting ways to think about communication (Chang, 2007; St. John, 2007, Striphas, 2007). Although knowledge translation connects to ideas of communication as progress, translation is problematized as a communicative practice when viewed in light of the still-dominant spiritualist tradition.

Rationalizing integrated knowledge translation as a way share specialized expertise implicitly values achieving a more unified knowledge. Bucknall (2012) exemplifies this view, writing that knowledge translation is an "international strategy focused on overcoming the fragmentation caused by discipline silos" (p. 193). In the face of this threat, Gibbons et al. (1994) argue that intense specialization of knowledge and its fragmentation into narrower areas signal the breakdown of any common understanding across disciplines, and the "impossibility of communication across specialisms" (Gibbons et al., 1994, p. 28).

As a result, efforts to better share and use research knowledge become "a kind of epistemological panacea, to act as a hedge against the threats of epistemological anarchy" (Salter \& Hearn, 1996b, p. 8). Levinas and Hand (1989) however, suggest that in the face of otherness, unification is merely a reductionist and an illusory response:

The theme of solitude and the breakdown in human communication are viewed by modern literature and thought as the fundamental obstacle to universal brotherhood...One begins with the idea that duality must be transformed into unity, and that social relations must culminate in communion. This is the last vestige of...idealism. (p. 164)

Yet, these ideals should not go unquestioned in knowledge translation research and practice. Achieving unified knowledge may not be possible, but more importantly, it may not be desirable. For example, Strier (2014) has challenged the dichotomy of dysfunctional conflict versus ideal unity, arguing instead that efforts to create, share and use knowledge emerge instead through "complex organizations characterized intermittently by both conflict and collaboration [emphasis added]" (p. 157).

\section{Lost in Translation}

The traditional valuing of "angelic" communication mirrors a tradition of devaluing translation as imperfect and secondary. Instead striving for perfect understanding, translation necessarily emphasizes "making do, misunderstanding, contingency, and difference" (Striphas, 2005, p. 234). So, if translation activities are implicitly measured against the normative ideal of perfect communication, they are inevitably "doomed to fail" (Arroyo, 1988, p. 33; Dizdar, 2009, p. 96). While these topics have been deeply explored in translation studies and communications studies literature, they have yet to emerge as major, explicit areas of inquiry in knowledge translation studies. However, the ways we think about the value and purpose of translating have significant implications for the knowledge translation community.

The simplest manifestation of this tension is the ubiquitous cliché "lost in translation," referencing the misunderstandings and loss of meaning that are assumed to inevitably result from a translation process (Munday, 2012). As a result of this certain loss of meaning, translations are often seen as degraded, inferior copies of the originals (Striphas, 2005, p. 234). Chamberlain (1988) outlined many ways in which translation has been figured literally in secondary terms, including the categorization of translations as "derivative works" in American copyright law (p. 455). In early studies of translation, Belloc (1931) argued that, because translation has been seen as a subsidiary art and 
derivative, neither its importance nor its difficulty has been grasped historically and translations have never been granted the dignity of original works (p. 32).

The assumed loss in translation extends to fears translation as threatening. Bassnett (2014) has argued translation is a reminder that no act of interpretation can be definitive, so it can therefore be seen as a dangerous, morally suspect, and potentially subversive act (p. 9). Dizdar (2009) has likewise argued that the possibility of perversion is, in fact, a constitutive trait of translation (p. 98). In not managing to transmit all of the original's meaning, the translation betrays of that which is not carried over. In other words, while the original abides what is "natural, truthful, and lawful," the translation is constructed in opposition, as "artificial, false, and treasonous" (Chamberlain, 1988, p. 455). The dangers of translation have been described in more vivid terms as well. In their survey of historical opinions of translation, Skibińska \& Blumczyński (2009) found translation viewed as "an organic, parasitic dependence. A translation grows out of the original and feeds on its juices" (p. 45). Concerns around the dangerous potential of translation have manifested throughout history. For example, Palsson (1994) has pointed to the fact that that some texts were carefully guarded against translation, and that translation was sometimes forbidden by rulers to prevent contamination of national texts by alien languages. These represented "attempts to avoid the corrupting influence of translation, erecting a boundary by insiders and outsiders by means of language" (Palsson, 1994, p. 15).

Although knowledge translation in its contemporary use is most often rhetorically constructed as progressively removing barriers to sharing information, concerns around translations have emerged in some respects. For example, many communication-focused studies have explored how aspects of scientific knowledge is distorted when communicated to other, non-scientific audiences (for example, Ireland, 2001; Lenfant, 2003; Manca \& Willan, 2006; Walters \& Walters, 1996). In just one of these many examples, Brechman, Lee and Cappella (2009) concluded that journalists and public relations professionals ultimately distort and sensationalize scientific knowledge when they attempt to communicate it to the public. This work follows the long tradition of painting translation as suspect and imperfect versus the untainted, original and the ideals of unmediated mind-to-mind communication.

Additionally, some of the suspicions or concerns of academics around the growing trend of knowledge translation can be traced to worries that their work will be distorted, misunderstood or misused as a result of the translation process. For example, in a qualitative study of academics' perceptions of knowledge translation, Paulin and Suneson (2012) reported that academics expressed fears that their research would begin to be evaluated by its translatability and value to outside communities, as opposed to its academic merits (p. 1514). Subsequently, there are fears that by translating academic work, the translations will contaminate or threaten the threaten rigor and objectivity of the academic works and academics themselves (Bowen \& Graham, 2013). Academics have also expressed fears that translating could misrepresent their research, worrying that translators might "over-sell" their research and risk raising public expectations too soon (Paulin \& Suneson, 2012, p. 1513). Additionally, there are concerns that inaccurate knowledge translation work will lead to misuse of scientific knowledge to fulfill political policy agendas in ways that betrays the original meaning of the research (Choi et al., 2005, p. 633). In a business context, Empson (2001) identified fears of exploitation and contamination of original knowledge as two key obstacles to successful knowledge translation between companies (p. 858). It is very possible similar concerns occur in academic environments. I recognize that many other factors disincentive knowledge translation within academia, including time and financial constraints, failure of promotion and tenure committees to recognize knowledge translation efforts, and concerns commoditizing knowledge, commercializing research and wrongly privileging applied technical research at the expense of oth- 
er areas (Bowen \& Graham, 2013). However, fears of loss in translation appear to be yet another obstacle to add to the list.

\section{The Subservient Translator}

Aligned with the disparaged image of translations is a similar view of translators themselves. Arroyo (1994) contends that, if translation is a form of imperfect communication or subversion, then the translator necessarily becomes a "betrayer" (p. 152). While the roles of translators have shifted over time and across different cultures, translators have generally been relegated to a marginal status, and often perceived to be subordinate to those for whom they are translating (Striphas, 2005, p. 234). Bassnet (2014) argues that this legacy of the servant-translator arose in the English-speaking world in the 19th century, where the translator came to be seen as an element in a master-servant relationship with the original author or speaker acting as an "overlord" (p. 15). Over time, translation came to be perceived as a low status occupation that entailed a mechanical rather than a creative process (Bassnett, 2014, p. 15). Venuti (1986) has identified another historical trend, in which translators are supposed to be invisible, in part because of the individualistic conceptions of authorship that prevail in Western cultures (p. 6). In other historical analyses, the translator has also been conceived as a rival of the author, or the translator is seen as a "mere copyist" (Skibińska \& Blumczyński, 2009, p. 37). All of these readings are potentially disempowering to people doing translation work.

While the literature on knowledge translation tends to advocate the importance and value of knowledge translators, often called "knowledge brokers", there is still a sense of privileging the author as a more authentic and therefore more ideal person to communicate their interior knowledge. Meyer (2010) argues both the need for and the numbers of knowledge brokers are increasing (p. 118). However, she is concerned that the marginal, peripheral position of knowledge brokers means they are often viewed with suspicion (Meyer, 2010 p. 122). As a result, knowledge brokering still tends to be unrecognized in academic institutions, and is most often an "invisible" activity that tends to take place "back stage" (Vogel \& Kaghan, 2001, p. 361).

Some advocates for knowledge translation call for researchers, or the "authors", to step into a translator role. For example, Azimi et al. (2015) have argued that there are often controversies about the accuracy and relevance of the translated knowledge because the translator often is not the original author of the academic work. To remedy this problem, they have suggested knowledge translation might be more promising, trustworthy and closer to ideal when translator and author are the same person (Azimi et al. 2015, p. 98). If the benchmark of communication is perfect, spiritto-spirit communication, then it makes sense to cut out the middlemen in the process.

\section{Recognizing Gain in Translation}

Many translation and communication scholars, however, have argued this subordinate status of translation need not be the case. El-dali (2012) argues:

It is an indication of the low status of translators and their work that so much time should have been spent on discussing what is lost in the transfer of a text from source language to target language whilst ignoring what can also be gained, for the translator can at times enrich or clarify the source text as a direct result of the translation process. (p. 766) 
Starting in the 1990s, Bassnett (2014) contends that translation stopped being perceived as a marginal activity, and began to be seen as a fundamental act of human exchange in the context of global expansion (p. 2). Bassett (2014) has posited that the field of translation studies has over the last two decades, rejected the old terminology of translation as the betrayal of an original in favour of translation as creative bridge building. Hatim and Mason (1990) likewise argued that developments in translation studies provided new directions that restore to the translator the central role in a process of cross-cultural communication (p. 756). Constantinescu (2013) has argued some of this shift comes from an increasing recognition that "our standard of success cannot be the perfect transmission of all aspects of a text or speech," and that "even when force or connotation is lost in the passage from one language to another, something may be gained, a glimpse of new meaning, or a resonance in the very gap between idioms."

Some scholars in translation and communication studies have noted that the emergence of postmodern theories of communication have powerfully deconstructed notions of intrinsic meaning and authority and contested the normative ideal of communication (Arroyo, 1998, p. 44). Arroyo (1998) has argued postmodern thinking in communication can be credited for liberating translation from "unrealistic expectations and dead end arguments" around the search for perfect transmission of meaning (Arroyo, 1998, p. 26). In this way, postmodern theories of language challenge the traditional view of translation as a transparent, impersonal activity, which is expected to recover and to be blindly faithful to the "stable meanings" of an author (Arroyo, 1994, p. 147-8). However, this postmodern shift in translation studies does not apply as clearly to the context of knowledge translation. While the evidence and knowledge at the heart of knowledge translation efforts is, of course, contextually constructed and understood, a key assumption of knowledge translation is the existence of some underlying, specific, and often scientific "knowledge," with intrinsic meaning that should be shared with someone to achieve practical ends. Harding (2000) has described this as "the hope that knowledge can be free from the shackles of context, its validity floating freely above time and space" (p. 23). If there is no original meaning to communicate, however, then what is the real goal of knowledge translation? In this way, knowledge translation very much subscribes to the enlightenment project of modernity, privileging rationality and knowledge as a means of utopic emancipation (Walker, 1998). Just how modernist values of knowledge translation interact with postmodernist theories of language could be interesting for further exploration, but it is beyond the scope of this article.

\section{Beneficial Assumptions of Translation}

Building on these alternative readings of translation, several assumptions emerge that could be beneficial to the knowledge translation community, by shining a potentially useful spotlight on questions of language, culture and boundaries, as well as the power relations within them.

Translation emphasizes language as the centerpiece of its work. This is especially useful in the context of knowledge translation, because the language of research evidence is highly specialized and often incomprehensible to non-specialists. For example, this short excerpt from a neuroscience journal discusses the findings of a study: "Functional assays have revealed that Amyloid Precursor Protein (APP) plays critical roles in synaptic plasticity, neurite outgrowth and synaptogenesis" (de Jesus Gonçalves et al., 2015). This excerpt could be translated as: "Scientists looked at the "Amyloid Precursor Protein" (APP), and how it functions while the brain is developing. They found that APP was involved in helping brain cells grow and building connections between them, which is important for learning and memory." This is only a brief example to show how intralingual translation is vital for those outside specialized areas of expertise to access and understand the expert 
knowledge that could be of use to them. In translation theory, it is now common practice to focus on the functionality of the translated text as a fundamental concern, while the translated text's relation to the source text is a secondary consideration (Mason, 2000, p. 1). In other words, this idea of translation privileges a functional understanding of the translation for the target audience over the idea that everything inferable from a source text must be relayed in a target text. As a result, translation requires constant awareness of all the relevant factors to produce a target text that fulfills the needs of its target audiences (Schjoldager, Gottlieb \& Klitgard, 2008, p. 20).

These theories of translation could be useful resources for knowledge translators. Yet, it is important to note that a focus solely on language could limit the effectiveness of knowledge translation. Bennett and Jessani (2001) argue that there are four possible reasons for the "do-know" gap-of which a lack of understanding is just one. The other three reasons are that people do not know that the information exists; they do not care and see the information as irrelevant, or that they do not agree and think the information is misguided or fake. Other aspects of communications and translation theorizing, however, can address these obstacles.

Translation can be understood to delineate cultural boundaries. Pym (1992) argues that, as we approach cultural boundaries, texts become increasingly difficult to understand, "until we give up and demand a translation" (p. 25). In this way, Pym (1992) argues we can define the limits of a culture as the boundaries across which texts transferred across time or space have had to be intralingually or interlingually translated (p. 25). Conceptualizing knowledge translation in this way highlights the different cultures involved in knowledge translation efforts, by assuming the situations where translation must take place delimitate cultural boundaries. In knowledge translation, this cultural, social focus of translation also emphasizes embodied communication, because it "points to human interaction as the engine that drives research into practice" and "implies the need for both human intermediaries between the worlds of research and action" (Lomas, 2007, p. 130).

Crapanzano (1997) argues that translation must also be understood in terms of power: "It is the product of a confrontation between two languages, two philosophies, two visions of the world embedded in these languages, two ways of constituting and evaluating these worlds" (p. 50). However, he contends the essentially contestatory nature of translation is often hidden by theories that stress reciprocity, harmony, or stated aims of perfectly clear communication and mutual understanding (Crapanzano, 1997, p. 50). A focus on translation across cultural boundaries that recognizes power also recognizes that dissimilar cultures produce, communicate and value knowledge differently (Caplan, 1979). For example, academic-researchers may prioritize the production of explicit forms of abstract knowledge such as theoretical academic papers, whereas clinical-professionals might use more tacit knowledge to inform practice (Bartunek, Trullen, Bonet \& Sauquet, 2003). Thus, Hatim (1990) has argued that translation asks us to "explore our ideologically and culturally based assumptions about all those matters on which we utter, in speech or in writing or in signs" which inevitably makes "strange and denaturalizes" the powers and outcomes of communication that are commonly taken for granted (Hatim, 1990, p. ix).

\section{Conclusion}

Knowledge translation is concerned with making the world a better place by using research to improve decision-making. Although the practice of applying research to so-called "real-world" settings has existed since people began a practice of research, knowledge translation as a formal term only emerged in the last 15 to 20 years, as one of a plethora of related terms. However similar these terms may be, they are not the same, and each term connotes different meanings and underlying assumptions. While mapping and comparing the various merits of each term relative to other terms 
is important, the reality is certain terms are already deeply entrenched in certain contexts. I have outlined how the term knowledge translation is particularly important in Canada context, and in the international health context. Although we can learn by comparing differences and similarities between terms, it is also productive to look more deeply at the potential assumptions, tensions, historical and contextual meanings embedded in the term. This analysis revealed that the contemporary assumptions and rhetoric around knowledge translation as a term do not necessarily align with traditional thinking about communication and translation, potentially affecting how knowledge translation work is perceived both within and outside of the knowledge translation community. We stand to gain from better understanding the implications of the term, both making it more robust, useful and rich, and avoiding reducing it to an empty buzzword.

This exercise in analysis is productive in strengthening interdisciplinary connections and highlighting new areas of potential interest for knowledge translation scholars. It opens up the rich field of translation studies, which has already grappled with many of the potential challenges that knowledge translation may face as a burgeoning field. It also draws more connections between knowledge translation and communications studies. Questions around power and different cultures that arise from looking more deeply at translation could be further connected to ideas of communication political economy and theories of agenda setting. This analysis also emphasizes the continued dominance of the spiritual tradition in communication thought, which, if not explicitly addressed, could negatively impact the perceived success of knowledge translation work.

I do not aim to champion knowledge translation as the best term to use, but rather to highlight how its underlying assumptions could have either beneficial or detrimental implications. Greenhalgh and Wieringa (2011) have argued that choosing and using a single term will "inadvertently close our minds to alternative framings which could add to the illumination and analysis of this complex field" (p. 507). They have further contended that we should resist becoming wedded to knowledge translation as a term--or any other single term--as its assumptions will become entrenched and ultimately limit our thinking (Greenhalgh and Wieringa, 2011, p. 508). However, for the sake of sanity for all those involved, I argue it can also be useful to make the term's assumptions explicit, and critically interrogate how they might affect thinking and practical work in knowledge translation. In this way, we can minimize the terminology problems while recognizing the significance of the terms we choose to use.

Those involved in knowledge translation should be aware that despite its rhetoric of progress and success, knowledge translation conflicts with the dominant ideals in communication and that under those exacting standards, it is fated to disappoint. Instead, knowledge translation must acknowledge that perfect communication is impossible, and that the messy work of translation can offer something potentially more valuable. Peters (1999) has argued the dream of perfect communication itself inhibits the hard work of connection:

Too often, communication misleads us from the task of building worlds together. It invites us into a world of unions without politics, understandings without language and souls without bodies, only to make politics, language and bodies reappear as obstacles rather than blessings. (pp. 30-31)

Rather than frame knowledge translation as a project doomed to fail, scholars in translation and communication studies can help those interested in the project of knowledge translation by carving out alternate paths forward. 


\section{References}

Armstrong, R., Waters, E., Roberts, H., Oliver, S., \& Popay, J. (2006). The role and theoretical evolution of knowledge translation and exchange in public health. Journal of Public Health, 28(4), 384389.

Arrojo, R. (1994). Fidelity and the gendered translation. TTR: traduction, terminologie, rédaction, $7(2), 147-163$.

Arrojo, R. (1998) The revision of the traditional gap between theory \& practice $\&$ the empowerment of translation in postmodern times. The Translator, 4(1), 25-48.

Azimi, A., Fattahi, R., \& Asadi-Lari, M. (2015). Comment \& Opinion: Knowledge translation status and barriers. Journal of the Medical Library Association, 103(2), 96-99.

Balka, E. (1991). Womantalk goes on-line: the use of computer networks in the context of feminist social change. Simon Fraser University.

Balka, E., Tolar, M., \& McCarthy, C. (2015) Knowledge Translation: What colours are the emperor's clothes?. Unpublished manuscript, School of Communication, Simon Fraser University, Burnaby, Canada.

Bartunek, J., Trullen, J., Bonet, E., \& Sauquet, A. (2003). Sharing and expanding academic and practitioner knowledge in health care. Journal of Health Services Research \& Policy, 8(suppl. 2), 62-68.

Bassnett, S. (2014). Translation studies (4th ed.). New York, NY: Routledge.

Bell, R. T. (1991). Translation and translating (Vol. 56). London, UK: Longman.

Belloc. H. (1931) On translation. Oxford, UK: The Clarendon Press.

Bennett, G., \& Jessani, N. (2011). The knowledge translation toolkit: Bridging the know-do gap: A resource for researchers. New Delhi, IN: Sage Publishing.

Berta, W., Teare, G. F., Gilbart, E., Ginsburg, L. S., Lemieux-Charles, L., Davis, D., \& Rappolt, S. (2010). Spanning the know-do gap: Understanding knowledge application and capacity in long-term care homes. Social Science and Medicine, 70(9), 1326-1334.

Bowen, S. J., \& Graham, I. D. (2013). From knowledge translation to engaged scholarship: Promoting research relevance and utilization. Archives of Physical Medicine and Rehabilitation, 94(1 suppl. 1), S3-S8.

Bowen, S. \& Martens, P. (2005). Demystifying knowledge translation: Learning from the community. Journal of Health Services Research \& Policy, 10(4), 203-211.

Brechman, J., Lee, C., \& Cappella, J. N. (2009). Lost in translation? A comparison of cancer-genetics reporting in the press release and its subsequent coverage in the press. Science Communication, 30(4), pp. 453-474.

Burns, F. (1998). Information for health an information strategy for the modern NHS 1998-2005. West Yorkshire, UK: National Health Service. Retrieved from http://webarchive.nationalarchives.gov.uk/20130107105354/http://www.dh.gov.uk/prod_con sum_dh/groups/dh_digitalassets/@dh/@en/documents/digitalasset/dh_4014469.pdf

Canadian Health Services Research Foundation. (1999). Resource document: Issues in linkage and exchange between researchers and decision makers. Retrieved from http://www.cfhifcass.ca/migrated/pdf/event_reports/linkage_e.pdf

Canadian Institutes of Health Research. (2014). Canadian health research: saving lives, making history. Retrieved from http://www.cihr-irsc.gc.ca/e/35216.html\#2000

Caplan, N. (1979). The two-communities theory and knowledge utilization. American Behavioral Scientist, 22(3), 459-70.

Carlyle, P. R. (2004). Transferring, translating, and transforming: An integrative framework for managing knowledge across boundaries. Organization Science, 15(5), 555-568. 
Chamberlain, L. (1988). Gender and the metaphorics of translation. Signs, 13(3), 454-472.

Chang, B. G. (2007). Deconstructing communication. In R. Craig \& H. Muller (Eds.) Theorizing communication: Readings across traditions (pp. 251-256). Los Angeles, CA: Sage Publications.

Choi, B. C., Pang, T., Lin, V., Puska, P., Sherman, G., Goddard, M., Ackland, M.J., Sainsbury, P., Stachenko, S., Morrison, H., \& Clottey, C. (2005). Can scientists and policy makers work together?. Journal of Epidemiology and Community Health, 59(8), 632-637.

Constantinescu, A. (2013). The role of translation in Borges's creative process. Linguistic and Philosophical Investigations, (12), 171-176.

Contandriopoulos, D., Lemire, M., Denis, J.-L., \& Tremblay, E. (2010). Knowledge Exchange Processes in Organizations and Policy Arenas: A Narrative Systematic Review of the Literature. Milbank Quarterly, 88(4), 444-483.

Cordero, C., Delino, R., Jeyaseelan, L., Lansang, M. A., Lozano, J. M., Kumar, S., \& Tugwell, P. (2008). Funding agencies in low-and middle-income countries: Support for knowledge translation. Bulletin of the World Health Organization, 86(7), 524-534.

Craig, R. T., \& Muller, H. (2007). Historical and Cultural Sources of Communication Theory. In R. Craig \& H. Muller (Eds.) Theorizing Communication: Readings across traditions (pp. 1-53). Los Angeles, CA: Sage Publications.

Crapanzano, V. (1997). Translation: Truth or metaphor. RES: Anthropology and Aesthetics, (32), 4551.

Crick, K., \& Hartling, L. (2015). Preferences of knowledge users for two formats of summarizing results from systematic reviews: Infographics and critical appraisals. PLOS ONE, 10(10), 1-8.

Davis, D., Davis, M. E., Jadad, A., Perrier, L., Rath, D., Ryan, D., Sibbald, G., Strauss, S., Rappolt, S., Wowk, M., \& Zwarenstein, M. (2003). The case for knowledge translation: Shortening the journey from evidence to effect. BMJ, 327(7405), 33-35.

de Jesus Gonçalves, R. G., Vasques, J. F., Trindade, P., Serfaty, C. A., Campello-Costa, P., \& FariaMelibeu, A. C. (2016). Nicotine-induced plasticity in the retinocollicular pathway: Evidence for involvement of amyloid precursor protein. Neuroscience, 313, 1-9.

Dizdar, D. (2009) Translational transitions: "Translation proper" and translation studies in the humanities. Translation Studies, 2(1) 89-102.

El-dali, H. M. (2012). Translation studies: Yesterday, Today and Tomorrow. International Journal of Asian Social Science, 2(6), 756-781.

Empson, L. (2001). Fear of exploitation and fear of contamination: Impediments to knowledge transfer in mergers between professional service firms. Human relations, 54(7), 839-862.

Estabrooks, C., Thompson, D. S., Lovely, J., Hofmeyer, A. (2006). A guide to knowledge translation theory. The Journal of Continuing Education in the Health Professions, 26, 25-36.

Everett, D. (2005). Cultural constraints on grammar and cognition in Pirahã: Another look at the design features of human language. Current Anthropology 46(4): 621-646.

Fiske, J. (1990). Introduction to communication studies (2nd ed.). New York, NY: Routledge.

Gagliardi, A. R., Fraser, N., Wright, F. C., Lemieux-Charles, L., \& Davis, D. (2008). Fostering knowledge exchange between researchers and decision-makers: Exploring the effectiveness of a mixed-methods approach. Health Policy, 86(1), 53-63.

Goldner, E. M., Jeffries, V., Bilsker, D., Jenkins, E., Menear, M., \& Petermann, L. (2011). Knowledge translation in mental health: A scoping review. Healthcare Policy, 7(2), 83-98.

Graham, I. D., Logan, J., Harrison, M. B., Straus, S. E., Tetroe, J., Caswell, W., \& Robinson, N. (2006). Lost in knowledge translation: Time for a map? Journal of Continuing Education in the Health Professions, 26(1), 13-24.

Green, L. W., Ottoson, J. M., Garcia, C., Hiatt, R. A. (2009). Diffusion theory and knowledge dissemina- 
tion, utilization, and integration in public health. Annual Review of Public Health, 30, 151-74.

Greenhalgh, T. (2010). What is this knowledge that we seek to 'exchange'. The Milbank Quarterly, 88(4), 492-499.

Greenhalgh, T., \& Wieringa, S. (2011). Is it time to drop the "knowledge translation" metaphor? A critical literature review. Journal of the Royal Society of Medicine, 104(12), 501-509.

Grimshaw, J. M., Eccles, M. P., Lavis, J. N., Hill, S. J., \& Squires, J. E. (2012). Knowledge translation of research findings. Implementation Science, 7(50), 1-7.

Harding, S. (2000). Should philosophies of science encode democratic ideals? In D. Kleinman (Ed.), Science, technology, and democracy. (pp. 121-138). Albany, NY: State University of New York.

Hatim, B., \& Mason, I. (1990). Discourse and the translator. New York, NY: Routledge.

Hatim B., \& Mason, I. (1996). The Translator as communicator. New York, NY: Routledge.

Heinsch, M., Gray, M., \& Sharland, E. (2016). Re-conceptualising the link between research and practice in social work: A literature review on knowledge utilisation. International Journal of Social Welfare, 25, 98-104.

Holden, N. J., \& Von Kortzfleisch, H. F. O. (2004). Why cross-cultural knowledge transfer is a form of translation in more ways than you think. Knowledge and Process Management, 11(2), 127-136.

Institute for Knowledge Mobilization (2014). Report on the Canadian knowledge mobilization forum $2014 \mathrm{~K}+$. Ottawa, ON. Retrieved from: http://www.knowledgemobilization.net

Ireland, M. (2001). Lost in translation. AJN The American Journal of Nursing, 101(6), 14.

Jacobson, N., Butterill, D., \& Goering, P. (2003). Development of a framework for knowledge translation: understanding user context. Journal of Health Services Research \& Policy, 8(2), 94-99.

Jacobson, N. (2007). Social epistemology theory for the "fourth wave" of knowledge transfer and exchange research. Science Communication, 29(1), 116-127.

Jakobson, R. (2000). On linguistic aspects of translation. In L. Venuti (ed.), The translation studies reader. (pp. 113-118). New York, NY: Routledge. (Original work published in 1959).

Katz, E. (2006). Rediscovering Gabriel Tarde. Political Communication, 23(3), 263-270.

Kerner, J. F., \& Hall, K. L. (2009). Research dissemination and diffusion: Translation within science and society. Research on Social Work Practice, 19(5), 519-530.

Kerner, J. F. (2006). Knowledge translation versus knowledge integration: A “funder's” perspective. The Journal of Continuing Education in the Health Professions, 26(1), 72-80.

"Knowledge." (2015). In Oxford English online dictionary. Retrieved from http://www.oxforddictionaries.com/definition/english/knowledge

Kirchhoff, K. T. (2004). State of the science of translational research: From demonstration projects. Worldviews on Evidence-Based Nursing, S6-S12.

Lang, E. S., Wyer, P. C., \& Haynes, R. B. (2007). Knowledge translation: Closing the evidence-topractice gap. Annals of Emergency Medicine, 49(3), 355-363.

Lenfant, C. (2003). Clinical research to clinical practice-lost in translation?. New England Journal of Medicine, 349(9), 868-874.

Liyanage, C., Elhag, T., Ballal, T., \& Li, Q. (2009). Knowledge communication and translation--a knowledge transfer model. Journal of Knowledge Management, 13(3), 118-131.

Lomas, J. (2007). The in-between world of knowledge brokering. BMJ: British Medical Journal, 129132.

Manca, A., \& Willan, A. R. (2006). Lost in translation. Pharmacoeconomics, 24(11), 1101-1119.

Major, E., \& Cordey-Hayes, M. (2000). Knowledge translation: A new perspective on knowledge transfer and foresight. Foresight, 2(4) 411 - 423.

Mason, I. (2000). Audience design in translating. The Translator, 6(1), 1-22.

Mattelart, A. (2007). The Invention of Communication. In R. Craig \& H. Muller (Eds.) Theorizing 
Communication: Readings across traditions (pp. 26 -36). Los Angeles, CA: Sage Publications.

McKeown, S., Krause, C., Shergill, M., Siu, A., \& Sweet, D. (2016). Gamification as a strategy to engage and motivate clinicians to improve care. Healthcare Management Forum, 29(2), 67-73.

McKibbon, K. A., Lokker, C., Wilczynski N. L., Ciliska, D., Dobbins, M., Davis, D.A., Haynes, R.B. \& Straus S. E. (2010). A cross-sectional study of the number and frequency of terms used to refer to knowledge translation in a body of health literature in 2006: A Tower of Babel? Implementation Science, 5(16).

Meyer, M. (2010). The rise of the knowledge broker. Science Communication, 32(1), 118-127.

Moat, K. A., Lavis, J. N., \& Abelson, J. (2013). How contexts and issues influence the use of policyrelevant research syntheses: A critical interpretive synthesis. Milbank Quarterly, 91(3), 604-648.

Munday, J. (2012). Introducing translation studies: Theories and applications (3rd ed.). New York, NY: Routledge.

Ogden, C. K., \& Richards, I. A. (2001). The meaning of meaning: A study of the influence of language upon thought and the science of symbolism. London, UK: Routledge.

Ottoson, J. M. (2009). Knowledge-for-action theories in evaluation: Knowledge utilization, diffusion, implementation, transfer, and translation. New Directions for Evaluation, 124, 7-20.

Palsson, G. (1994). Beyond boundaries: Understanding, translation and anthropological discourse. Providence, RI: Berg Publishers Limited.

Paulin, D., \& Suneson, K. (2012). Knowledge transfer, knowledge sharing and knowledge barriers: Three blurry terms in KM. The Electronic Journal of Knowledge Management, 10(1), 81-91.

Patton, M. Q. (2016). What is Essential in Developmental Evaluation? On Integrity, Fidelity, Adultery, Abstinence, Impotence, Long-Term Commitment, Integrity, and Sensitivity in Implementing Evaluation Models. American Journal of Evaluation, 37(2), 250-265.

Perlovsky, L. (2009). Language and emotions: Emotional Sapir-Whorf hypothesis. Neural Networks, 22(5-6), 518-526.

Peters, J. D. (1999). Speaking into the air. Chicago, IL: University of Chicago Press.

Pym, A., (1992). Translation and text transfer: An essay on the principle of intercultural communication. Frankfurt, DE: Peter Lang.

Reboul, A. (2012). Language: Between cognition, communication and culture. Pragmatics \& Cognition, 20(2), 295-316.

Rogers, E. (2003). Diffusion of Innovation (5th ed.). New York, NY: Free Press.

Rycroft-Malone, J. (2007). Theory and knowledge translation: Setting some coordinates. Nursing Research, 56(4), S78-S85.

Schjoldager, A., Gottlieb, H., \& Klitgard, I. (2008). Understanding Translation. Palo Alto, CA: Academia.

Scott, S. D., Estabrooks, C. A., Allen, M., \& Pollock, C. (2008). A context of uncertainty: How context shapes nurses' research utilization behaviors. Qualitative Health Research, 18(3), 347-357.

Shannon, C. E., \& Weaver, W. (1949). The Mathematical Theory of Communication. Urbana, IL: University of Illinois.

Shaxson, L., \& Alex T. Bielak. (2012). Expanding our understanding of K*(KT, KE, KTT, KMb, KB, KM, etc.). United Nations University Institute for Water, Environment and Health. Hamilton, ON.

Skerrett, D. M., (2010) Can the Sapir-Whorf hypothesis save the planet? Lessons from cross-cultural psychology for critical language policy. Current Issues in Language Planning, 11(4), 331-340.

Skibińska, E., \& Blumczyński, P. (2009). Polish metaphorical perceptions of the translator and translation. International Journal on Translation Studies, 21(1), 30-57.

Smith, K., \& Stewart, E. (2017). We need to talk about impact: Why social policy academics need to engage with the UK's research impact agenda. Journal of Social Policy, 46(1), 109-127. 
Social Science and Humanities Research Council. (2009). SSHRC'S Knowledge Mobilization Strategy: 2009-11. Ottawa, ON. Retrieved from http://www.sshrc-crsh.gc.ca

Srivastava, J., \& Moreland, J. J. (2012). Diffusion of innovations: Communication evolution and influences. The Communication Review, 15(4), 294-312.

St. John, J. (2006). Communication as Failure. In G. J. Shepherd, J. St. John \& T. Striphas (Eds.), Communication as practice (249-256). Thousand Oaks, CA: Sage Publications.

Straus, S. E., Tetroe, J., \& Graham, I. (2009). Defining knowledge translation. CMAJ, 181(3-4): 165168.

Striphas, T. (2006). Communication as translation. In G. J. Shepherd, J. St. John \& T. Striphas (Eds.), Communication as practice (38-47). Thousand Oaks, CA: Sage Publications.

Tabak, R. G., Khoong, E. C., Chambers, D. A., \& Brownson, R. C. (2012). Bridging research and practice: Models for dissemination and implementation research. American Journal of Preventive Medicine, 43(3), 337-350.

Tetroe J. M., Graham I. D., Foy R., Robinson N., Eccles M.P., Wensing M., Durieux, P., Légaré, F., Palmhøj Nielsen, C., Adily, A., Ward, J. E., Porter, C., Shea, B., \& Grimshaw J. M. (2008). Health research funding agencies' support and promotion of knowledge translation: An international study. The Milbank Quarterly, 86(1), 125-155.

"Translation" (2015). In Merriam-Webster Online Dictionary. Retrieved from http://www.merriamwebster.com/dictionary/translation

Venuti, L. (1986). The translator's invisibility. Criticism, 28(2), 179-212.

Vogel, A., \& Kaghan, W. N. (2001). Bureaucrats, brokers, and the entrepreneurial university. Organization, 8, 358-364.

Wokler, R. (1998) The Enlightenment Project as Betrayed by Modernity, History of European Ideas, 24(4-5), 301-313.

Walters, L. M., \& Walters, T. N. (1996). It loses something in the translation: Syntax and survival of key works in science and conscience press releases. Science Communication, 18(2), pp. 165-180.

Ward, V., House, A., \& Hamer, S. (2009). Developing a framework for transferring knowledge into action: A thematic analysis of the literature. Journal of Health Services Research \& Policy, 14(3), 156-164.

Ward, V. (2017). Why, whose, what and how? A framework for knowledge mobilisers. Evidence \& Policy, 13(3), 477-497.

Woolf, S. H. (2008). The meaning of translational research and why it matters. JAMA, 299(2), 211213.

World Health Organization. (2004). World report on knowledge for better health: Strengthening health systems. Geneva, Switzerland. Retrieved from http://www.who.int/rpc/meetings/en/world_report_on_knowledge_for_better_health2.pdf

Yu, Lotman, M., Uspensky, B. A., \& Mihaychuk, G. (1978). On the semiotic mechanism of culture. New Literary History, 9(2), 211-232. 